\title{
Adaptive Noise Reduction Algorithm for an Image Based on a Bayesian Method
}

\author{
Yeong-Hwa Kim ${ }^{1, a}$, Jiho $\mathrm{Nam}^{b}$ \\ ${ }^{a}$ Department of Applied Statistics, Chung-Ang University; ${ }^{b}$ Korea Institute of Oriental Medicine
}

\begin{abstract}
Noise reduction is an important issue in the field of image processing because image noise lowers the quality of the original pure image. The basic difficulty is that the noise and the signal are not easily distinguished. Simple smoothing is the most basic and important procedure to effectively remove the noise; however, the weakness is that the feature area is simultaneously blurred. In this research, we use ways to measure the degree of noise with respect to the degree of image features and propose a Bayesian noise reduction method based on MAP (maximum a posteriori). Simulation results show that the proposed adaptive noise reduction algorithm using Bayesian MAP provides good performance regardless of the level of noise variance.
\end{abstract}

Keywords: Bartlett's test, Bayesian statistics, image processing, MAP, noise, noise reduction.

\section{1. 서론}

영상재현 장치의 궁극적인 목적은 원래의 이미지를 그대로 재현하는 것이다. 그러나 원래의 영상 에 통제할 수 없는 여러 가지 불가피한 원인으로 인해 영상에 잡음(noise)이 추가되게 되며, 따라서 영 상 잡음을 제거하거나 이를 최대한 줄이는 잡음제거(noise reduction)는 영상처리 분야에 있어서 매우 중요한 이슈이다. Kim과 Lee (2005), Lee 등 (2008)은 기존의 잡음제거의 문제점을 설명하였으며, 이 러한 문제점을 해결하기 위해서 통계적 가설 검정 기법을 사용한 영상 잡음제거 알고리즘을 제안하였 다.

본 연구에서는 베이지안 추정 방법을 이용하여 영상 잡음을 제거하는 알고리즘 가운데 하나인 $\mathrm{MAP}$ (maximum a posteriori)를 소개하고, 이 방법의 문제점을 제시하며, 이 문제점을 보완한 새로운 알 고리즘을 제안하고자 한다. 베이지안 추정 방법은 어떤 확률변수의 사전 분포를 알고 있을 때, 관측된 정보로부터 원래의 정보를 추정할 수 있는 방법으로 영상처리 분야에서 원본 영상을 복구할 때 널리 사 용되고 있는 방법 중의 하나이다.

본 연구에서는 영상 잡음 영역, 영상 특징 영역, 영상 잡음과 영상 특징이 섞여 있는 영역을 구분하 지 못하고 추정하는 MAP의 문제점을 보완하여 영역을 구분하고, 더 나아가 영상 잡음과 영상 특징의 상대적인 크기를 수치화하고자 한다. Kim과 Lee (2005)는 영상에서 영상 특징 영역과 영상 잡음 영역 을 효율적으로 구분하는 새로운 통계적 알고리즘을 제안하였으며, Lee 등 (2008)은 이를 통계적 가설 검정 방법에 적용하여 영상 특징의 정도를 측정하였다. 본 연구에서는 Lee 등 (2008)이 제안한 방법 가 운데 가장 효과적이었던 바틀렛(Bartlett) 검정을 사용하여 영상 특징의 정도를 측정한 결과를 바탕으로

This research was supported by Basic Science Research Program through the National Research Foundation of Korea(NRF) funded by the Ministry of Education, Science and Technology (NRF-2011-0026770).

${ }^{1}$ Corresponding author: Professor, Department of Applied Statistics, Chung-Ang University, Seoul 156-756, Korea.

E-mail: gogators@cau.ac.kr 


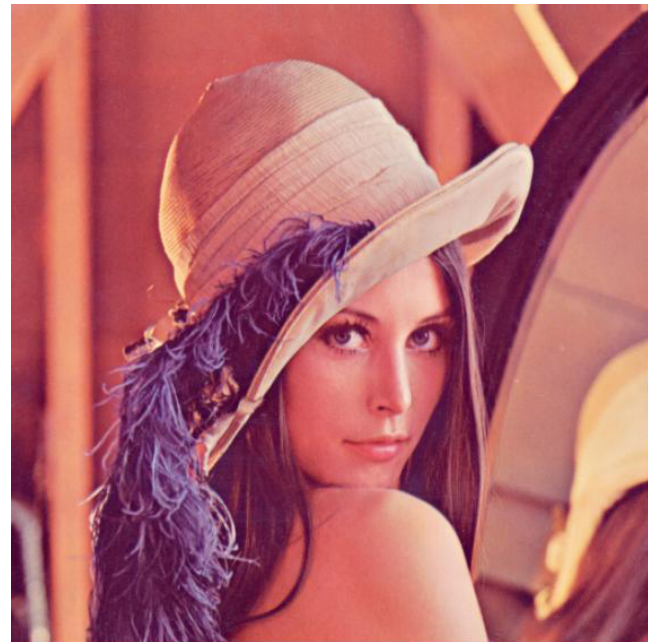

Figure 1: 'Lenna' pure image

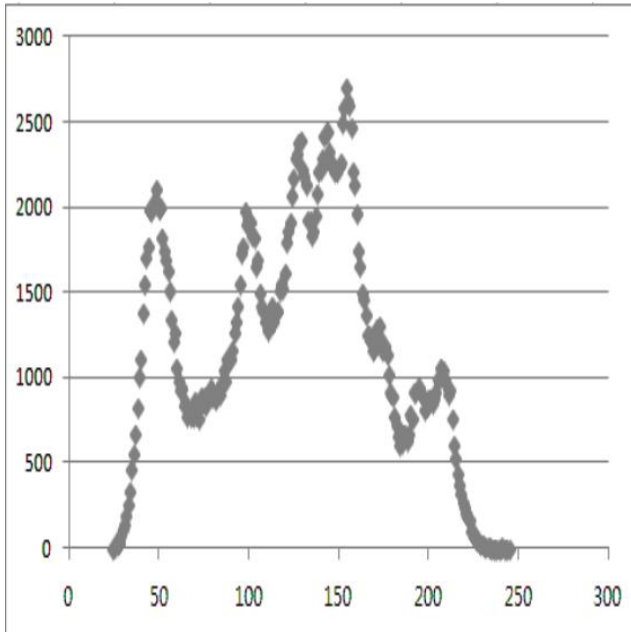

Figure 2: Histogram for 'Lenna'

적응적 MAP 알고리즘을 제시하고, 그 효용성을 일반적인 MAP 알고리즘과 바틀렛(Bartlett) 검정, 레 빈(Levin) 검정, 크루스칼-왈리스(Kruskal-Wallis) 검정에 근거한 적응적 단순 평활법의 결과와 비교한 다.

\section{MAP(Maximum a posteriori)}

영상 잡음 제거방법 중 하나인 $\mathrm{MAP}($ maximum a posteriori)는 사후분포의 최빈값을 이용하는 베이 지안 추정방법이며, 사후최빈값(posterior mode)은 다음과 같이 사후분포 $p(\theta \mid y)$ 를 최대화하는 값이다.

$$
\hat{\theta}_{M A P}=\arg \max p(y \mid \theta) \pi(\theta) .
$$

또한 사후최빈값은 다음과 같이 정의되는 고전적 최대 우도 추정량(maximum likelihood estimator)에 대응하는 베이지안 추정량이다.

$$
\hat{\theta}_{M L}=\arg \max p(y \mid \theta) .
$$

사전분포와 데이터의 정보가 주어졌을 때 $\theta$ 의 '가장 가능도가 높은(most likely)'값이라는 의미를 갖는 사후최빈값은 사전분포 $\pi(\theta)$ 가 편편한(flat) 경우, 고전적 최대 우도 추정량과 같아지게 된다. 영 상처리에서 $\theta$ 는 영상 잡음이 없는 원본 이미지의 화소(pixel)의 값을, $y$ 는 영상 잡음이 추가되어 있는 실 제 관측된 이미지의 화소값을 나타낸다.

$\mathrm{MAP}$ 를 통한 영상 잡음 제거 과정을 간략히 살펴보도록 한다. 다양한 영상 채집 장치를 사용하여 얻어지는 영상 이미지를 구현장치를 통하여 재생할 때 여러 가지 이유로 인하여 잡음이 더해지게 되 는 것이 일반적이다. 따라서 영상 잡음이 없는 순수 영상 이미지의 사전분포를 영상처리 분야에서 널 리 사용되는 몇 가지 원본 영상을 통해 흡사한 사전분포를 알아보는 것은 의미있는 것이라 할 수 있다. Figure 1은 영상처리 분야에서 널리 사용되는 'Lenna' 영상이미지이며, Figure 2는 Figure 1에 대한 히 스토그램이다.

히스토그램이란, 화소가 가진 명암 값들을 막대 그래프로 표현한 것으로 화소가 가질 수 있는 명암 값은 $x$ 축, 각 명암 값이 가진 빈도수는 $y$ 축에 표현한다. 어두운 영상은 화소값 분포가 왼쪽으로 편중 


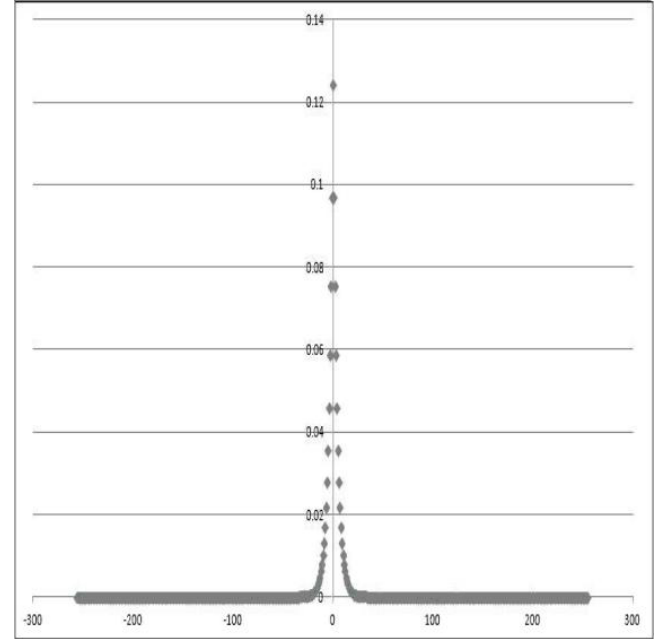

Figure 3: Histogram for the prior

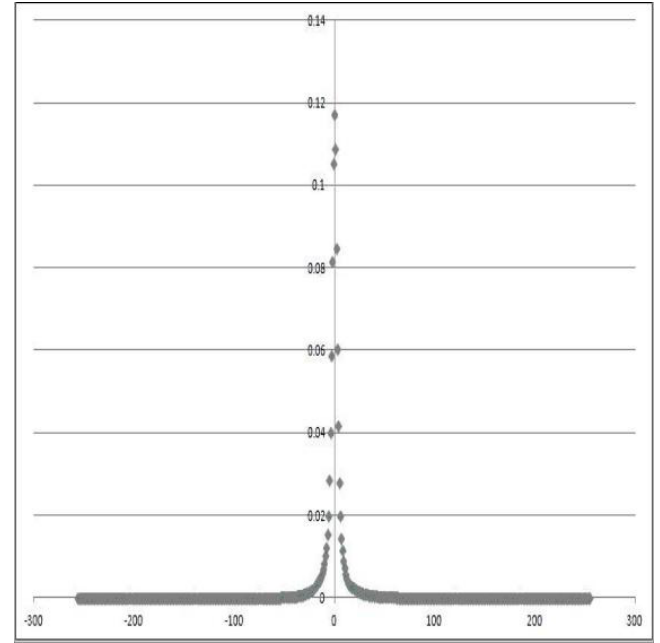

Figure 4: Histogram for 'Lenna' after highpass filtering

된 히스토그램을 가지며, 밝은 영상은 화소값 분포가 오른쪽으로 편중된 히스토그램을 갖게 된다. 즉, Figure 1의 각 화소의 명암 값들의 빈도 그래프를 그린 것이 Figure 2가 된다. 그러나, 사전분포가 일반 적으로 알려져 있는 모양이 아니라 그 분포를 통한 확률 계산이 어려우며, 또한 Figure 2 와 같은 분포는 각 영상마다 다른 모양을 나타내므로 이는 모든 영상에 적용할 사전분포로는 적합하지 않기 때문에 사 전분포를 이용하는 베이지안 추론방법에서는 Figure 2 와 같은 분포를 사용하기 어렵다. 그러나 사전분 포를 이용하는 베이지안 추론방법에서는 Figure 2 와 같은 분포를 사전분포로 사용하기 어렵다. 왜냐하 면, Figure 2와 같은 분포는 각 영상마다 다른 모양을 가지므로 모든 영상에 적용할 사전 분포로는 적합 하지 않기 때문이다. 따라서 원본 영상에 고주파 통과 필터(high-pass filter)를 처리한 영상을 사용하게 된다. 그 이유는 제거하고자 하는 영상의 잡음이 주로 고주파이기도 하며, 고주파 통과 필터를 사용한 다수의 이미지의 명암 값의 분포, 즉 히스토그램의 모양이 다음의 사전분포와 흡사하기 때문이다. 영 상처리에서 일반적으로 Mallat (1989), Simoncelli와 Adelson (1996)에서 사용한 다음과 같은 사전분포 를 사용한다.

$$
p(x)=c e^{-\frac{|x|}{\gamma}}
$$

여기서 $c$ 는 정규화 상수, $\gamma$ 는 보통 1 로 가정한다.

다음 Figure 3 Figure 6은 앞에서 언급한 사전분포의 히스토그램과 영상처리에서 샘플이미지로 자 주 사용되는 세 가지의 원본 영상(Lenna, Tiffany, Barbara)의 고주파 통과 필터 처리 후의 히스토그램을 비교한 것이다. 히스토그램을 비교해보면, 사전분포가 고주파 통과 필터 처리 후의 원본영상 히스토그 램을 잘 표현하고 있기 때문에 사전분포로 사용하여도 무방하다는 것을 알 수 있다.

영상 잡음의 분포가 $N\left(\theta, \sigma^{2}\right)$ 라고 한다면, $p(y \mid \theta)=1 /(\sigma \sqrt{2 \pi}) e^{-(y-\theta)^{2} /\left(2 \sigma^{2}\right)}$ 라고 할 수 있으며, $p(\theta \mid y) \propto$ $p(y \mid \theta) \pi(\theta)$ 를 통해서 $p(\theta \mid y)$ 를 최대화하는 순수 영상의 화소값 $\theta$ 를 구할 수 있다. 영상 잡음의 분산인 $\sigma^{2}$ 는 Kim과 Nam (2009)의 방법을 통해서 계산하였으며, 다음 Figure 7과 Figure 8은 Lenna 영상에 잡 음의 $\sigma$ 값이 10 이고, 영상 잡음이 추가되어 실제 관측된 영상의 화소값 $y$ 가 50 일 때의 $p(y \mid \theta)$ 와 $p(\theta \mid y)$ 의 히스토그램이다.

$\mathrm{MAP}$ 는 사후분포 $p(\theta \mid y)$ 를 최대화하는 값, 즉 앞의 Figure 8 에서는 37 이라는 값이 된다. 그러나, 이 


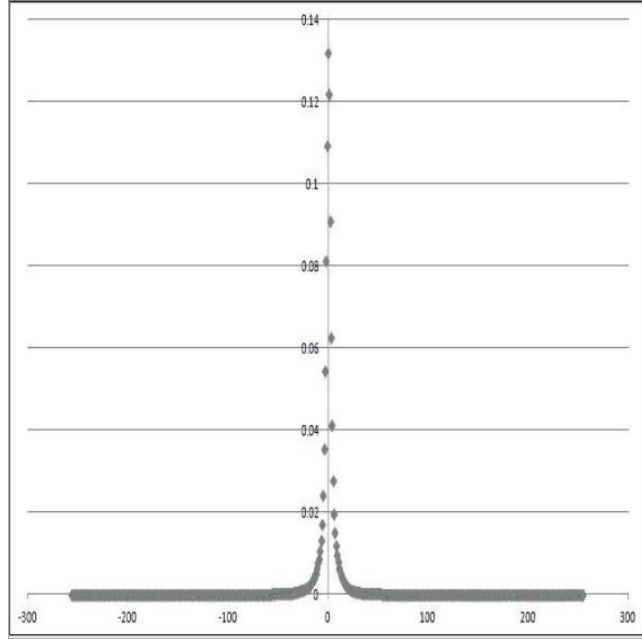

Figure 5: Histogram for 'Tiffany' after highpass filtering

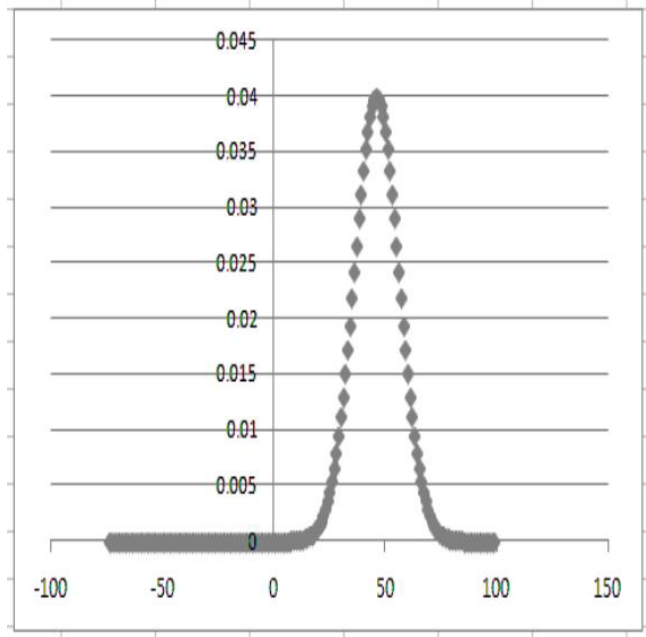

Figure 7: Histogram for 'Lenna' $+N\left(0,10^{2}\right) a f$ ter high-pass filtering

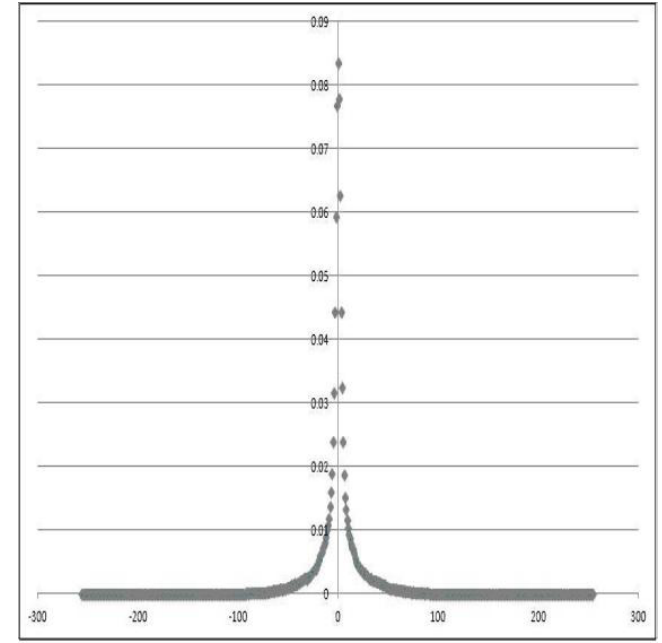

Figure 6: Histogram for 'Barbara' after highpass filtering

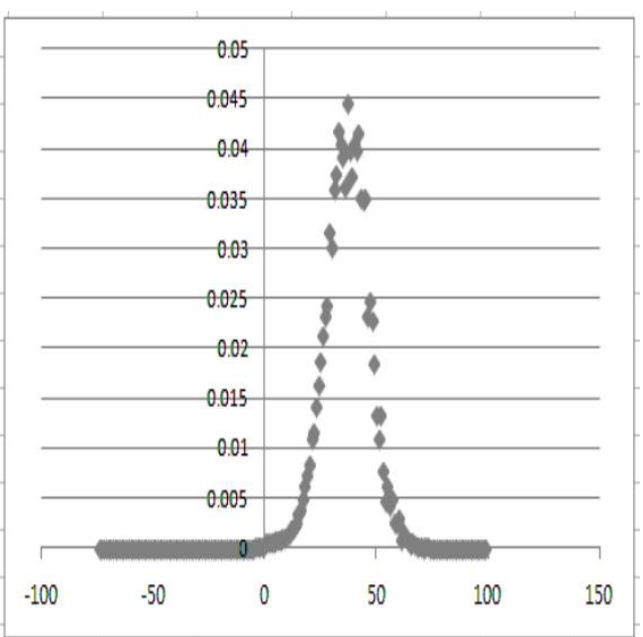

Figure 8: Histogram for the posterior

방법은 전체 영상의 데이터 값을 이용하여 분포를 통한 추론방식이기 때문에, 주변에 위치한 화소간의 관계를 파악하기는 어렵다. 예를 들어, 영상 잡음이 추가된 한 영상에서 똑같은 $\mathrm{A}$ 라는 값을 갖는 화 소가 두 개가 있다고 한다면, MAP 방법을 통한 추론에서는 두 개의 화소값은 동일하게 $\mathrm{B}$ 라는 화소값 으로 추론하게 될 것이다. 즉, $\mathrm{A}$ 라는 동일한 화소값을 가지고 있더라도, 하나는 영상 잡음이 추가되어 $\mathrm{A}$ 라는 값이 되었고, 다른 하나는 영상잡음이 추가되지 않은 상태로 $\mathrm{A}$ 라는 값을 가지고 있다면, 영상 특 징 영역과 영상 잡음 영역을 고려하지 못한 문제점이 발생할 수 있게 된다. 이처럼 MAP 방법에서는 단 순 평활법(simple smoothing)과 같이 대상 영역의 값들을 합하여 분산시킴으로서 영상 특징 영역에서 열화 현상을 발생시키게 된다. 따라서 영상 특징 영역과 영상 잡음 영역을 고려한 적응적 MAP 방법을 

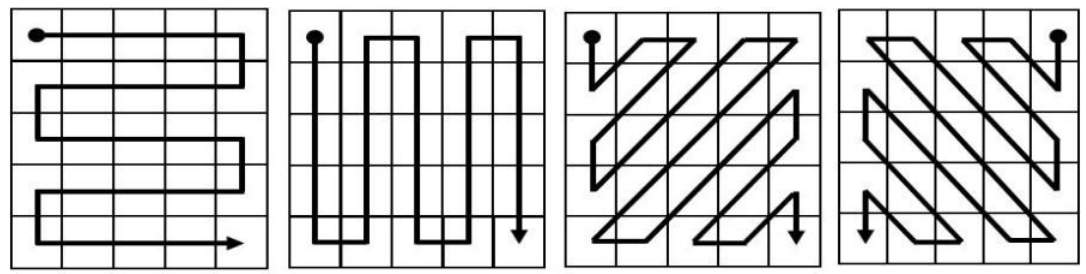

Figure 9: Example of rearranging pixels in four orientations

사용하는 것이 합리적인 방법이라 할 수 있다.

\section{3. 영상 특징과 영상 잡음 구분 알고리즘과 적응적 MAP}

\section{1. 영상 특징과 영상 잡음 구분에 대한 통계적 가설}

Kim과 Lee (2005)는 통계적 가설 검정에 근거하여 영상에서 영상 특징과 영상 잡음을 효율적으로 구분하는 아이디어와 검정절차에 관한 알고리즘을 제안하였다. 이 알고리즘의 기본적인 아이디어는 영상을 일정 크기의 블록으로 나누어 보았을 때 영상 특징이 존재하는 영역은 최소한 한 방향 이상으로 영상의 화소값들 사이에 강한 상관관계가 존재하며, 영상 잡음이 존재하는 영역에서는 영상 잡음이 일 정한 패턴이 없이 랜덤하게 생성되기 때문에 어떤 방향에 대해서도 상관관계가 존재하지 않는다는 것 이다. 이 상관관계를 추정하기 위하여 일정 크기의 픽셀 윈도우 내부의 화소값들을 특정한 방향에 대 하여 재배열하였다.

먼저 $M_{i j}^{N}$ 는 중심이 $x_{i j}$ 이고 크기가 $N \times N$ 인 픽셀 윈도우라 하고, $U^{\theta}=\left\{u_{1}^{\theta}, u_{2}^{\theta}, \ldots, u_{N^{2}}^{\theta}\right\}$ 는 특정한 방 향 $\theta$ 에 대하여 $M_{i j}^{N}$ 의 화소값을 재배열시킨 벡터라고 정의한다. 여기서 방향을 나타내는 $\theta$ 는 $n$ 개의 각 도, 즉 $\theta=\left\{\theta_{1}, \theta_{2}, \ldots, \theta_{n}\right\}$ 를 가정한다. 예를 들어, 픽셀 윈도우의 크기는 $N=5$, 방향의 수는 $n=4$ 이고 $\theta=\left\{0^{\circ}, 45^{\circ}, 90^{\circ}, 135^{\circ}\right\}$ 인 경우 화소값을 재배열하는 방법은 Kim과 Lee (2005), Kim과 Nam (2008), 그 리고 Kim과 Nam (2009)의 방법과 같으며, 이를 예시한 것이 다음 Figure 9이다.

Figure 9 와 같이 픽셀을 재배열한 후, 특정한 방향 $\theta$ 에 대하여 화소값들의 상관관계를 알아보기 위 하여 다음과 같은 벡터를 생성한다.

$$
Z^{\theta}=\left\{z_{2}^{\theta}, z_{3}^{\theta}, \ldots, z_{N^{2}}^{\theta}\right\}
$$

여기서 벡터의 원소는 $\theta=1,2, \ldots, n$ 과 $k=2,3, \ldots, N^{2}$ 에 대하여 $z_{k}^{\theta}=u_{k}^{\theta}-u_{k-1}^{\theta}$ 로 정의한다. 왜냐하면, 특정한 방향 $\theta$ 에 대하여 재배열된 픽셀들의 인접한 값의 차인 $z_{k}^{\theta}$ 가 만일 $\theta$ 방향으로 영상 특징이 존재할 경우에는 비슷하거나 같은 화소값을 가지기 때문에 아주 작고 유사한 값들을 가질 것이며, 영상 특징이 존재하지 않아 상관관계가 없는 경우에는 상대적으로 다른 값들을 가질 것이기 때문이다. 따라서 $\theta$ 방 향으로 영상 특징이 존재할 경우 $Z^{\theta}$ 의 변동은 다른 방향 $\theta^{*}(\neq \theta)$ 에 대한 $Z^{\theta *}$ 의 변동에 비하여 작게 될 것이다. 즉, 특정 방향으로 영상 특징이 존재하는가에 대한 문제는 $Z^{\theta}(\theta=1,2, \ldots, n)$ 의 값들의 분산의 동일성 검정 문제로 변환할 수 있다.

\section{2. 분산의 동일성 검정 방법}

임의의 픽셀 윈도우 $M_{i j}^{N}$ 에 영상 특징이 존재하는가, 즉 방향성이 존재하는가를 검정하는 경우의 영 
가설과 대립가설은 다음과 같다.

$$
\begin{aligned}
& H_{0}: M_{i j}^{N} \text { 는 순수한 잡음만을 포함한다. } \\
& H_{1}: M_{i j}^{N} \text { 는 영상 특징을 포함한다. }
\end{aligned}
$$

위의 가설은 앞서 설명한 바와 같이 분산의 동일성에 대한 다음과 같은 영가설과 대립가설로 변환 할 수 있다.

$$
\begin{aligned}
& H_{0}: \sigma_{1}^{2}=\sigma_{2}^{2}=\cdots=\sigma_{n}^{2} \\
& H_{1}: H_{0} \text { 은 사실이 아니다. }
\end{aligned}
$$

위 가설에서 $\sigma_{\theta}^{2}$ 은 $Z^{\theta}(\theta=1,2, \ldots, n)$ 의 모분산을 의미한다. 본 연구에서는 $\operatorname{Kim}$ 과 $\operatorname{Nam}(2007,2008)$, Lee 등 (2008)이 고려하였던 모수적(parametric), 준모수적(semi-parametric), 비모수적(nonparametric) 인 검정 방법인 바틀렛(Bartlett) 검정, 레빈(Levene) 검정, 크루스칼-왈리스(Kruskal-Wallis) 검정방법 에 근거하여 위의 가설을 검정하고, 그 결과에 따라 잡음에 대한 영상 특징의 상대적인 크기를 추정하 여 적응적 단순 평활법에 적용하였다. 또한 Lee 등 (2008)이 고려하였던 방법 가운데 가장 효과적이었 던 바틀렛(Bartlett) 검정에 근거한 영상 특징의 척도 추정 결과를 MAP에 적용하여 적응적으로 잡음제 거 처리를 시행한다. 앞서 열거한 세 가지 검정 방법에 Kim과 Nam (2007), Lee 등 (2008)에서 언급한 것과 그 내용이 동일하며 여기서는 바틀렛 검정 절차만 소개하기로 한다.

\section{3. 바틀렛 검정}

위 가설은 $n$ 개 모집단의 등분산(equal variance)에 대한 것으로서 이에 대한 검정 방법으로 본 연구 에서는 Lee 등 (2008)이 제안한 방법 가운데 가장 효과적이었던 바틀렛 검정을 사용하여 검정하고, 검 정결과를 바탕으로 영상 특징의 정도를 측정하기로 한다.

바틀렛 검정 (Bartlett, 1937)은 두 개 이상의 표본들의 모분산의 동일성을 검정하는 방법 중 대표적 인 것으로 표본들이 정규분포에서 추출된 확률표본임을 가정한다. 이 검정 방법은 표본이 정규분포를 따르지 않을 경우에 심각한 영향을 받는 것으로 알려져 있으나 영상처리 분야에서는 영상 잡음이 정규 분포를 따른다고 가정하는 것이 일반적인 경향이므로 이 방법을 사용하는 것에는 문제가 없다고 할 수 있겠다. 바틀렛 검정의 검정통계량 $G$ 는 다음과 같이 정의된다.

$$
G=\frac{(L-n) \ln s_{p}^{2}-\left(N^{2}-2\right) \sum_{\theta=1}^{n} \ln s_{\theta}^{2}}{1+\frac{1}{3(n-1)}\left\{\frac{n}{N^{2}-2}-\frac{1}{L-n}\right\}},
$$

여기서 $s_{\theta}^{2}$ 은 $Z^{\theta}=\left\{z_{2}^{\theta}, z_{3}^{\theta}, \ldots, z_{N^{2}}^{\theta}\right\}$ 의 표본분산, $L=n\left(N^{2}-1\right), s_{p}^{2}$ 은 합동표본분산(pooled sample variance)을 나타낸다. 합동표본분산은 표본분산들의 가중평균으로 다음과 같이 정의된다.

$$
s_{p}^{2}=\frac{N^{2}-2}{L-n} \sum_{\theta=1}^{n} s_{\theta}^{2} .
$$

바틀렛 검정에서는 $G>\chi^{2}(\alpha ; n-1)$ 이면, 모분산이 모두 동일하다는 영가설을 기각하게 된다. 여 기서 $\chi^{2}(\alpha ; n-1)$ 은 자유도가 $n-1$ 인 카이제곱 분포의 상위 $\alpha$-백분위수를 나타낸다. 


\section{4. 영상의 특징에 대한 척도}

Lee 등 (2008)은 바틀렛 검정 절차에 의거하여 중심이 $x_{i j}$ 인 블록 $M_{i j}^{N}$ 에 영상 특징과 영상 잡음이 어 느 정도 비율로 섞여 있는지를 나타내는 측도 $\delta(i, j)$ 를 다음과 같이 제안하였다.

먼저 주어진 $\alpha_{0}$ 와 $\alpha_{1}$ 에 대하여 $P\left(G<C_{0}\right)=\alpha_{0}$ 와 $P\left(G>C_{1}\right)=\alpha_{1}$ 을 만족하는 두 임계치 $C_{0}$ 와 $C_{1}$ 을 고려한다. 즉, 영가설을 채택하는 영역과 기각하는 영역, 결정을 유보하여 일종의 퍼지(fuzzy) 방 법을 적용하는 영역으로 구분한다. 여기서 $\alpha_{0}$ 는 영가설을 채택할 확률, $\alpha_{1}$ 은 영가설을 기각할 확률, 그 리고 $G$ 는 바틀렛 검정의 검정통계량을 나타낸다. $\alpha_{1}$ 의 값은 일반적인 가설 검정에서와 같이 0.05 를 사 용하였으며, $\alpha_{0}$ 의 값은 매우 작은 확률값 0.001 을 사용하였다. $G$ 를 이용하여 측도 $\delta_{i j}$ 의 값은 다음과 같이 세 가지의 경우 중에서 하나로 결정한다.

1. $G<C_{0}$ 인 경우에는 영가설을 채택하여 영상 특징이 존재하지 않는 순수한 영상 잡음이라고 결론을 내리며, 이때 $\delta_{i j}=0$ 이라고 정의한다.

2. $G>C_{1}$ 인 경우에는 영가설을 기각하여 영상 잡음이 존재하지 않는 순수한 영상 특징이라고 결론을 내리며, 이때 $\delta_{i j}=1$ 이라고 정의한다.

3. $C_{0} \leq G \leq C_{1}$ 인 경우에는 $G$ 의 값에 비례하도록 $\delta_{i j}$ 의 값을 다음과 같이 구한다.

$$
\delta_{i j}=\frac{G-C_{0}}{C_{1}-C_{0}} .
$$

\section{5. 적응적 $\mathrm{MAP}$}

2 장에서 언급한 $\mathrm{MAP}$ 의 문제점을 해결하기 위해서 앞에서 제안한 $\delta_{i j}$ 값을 이용하여 $\delta_{i j}=0$ (순수 잡음)일 때는 $\mathrm{MAP}$ 처리 값을, $\delta_{i j}=1$ (영상 특징)일 때는 관찰된 영상 화소값을, 영상 특징과 영상 잡 음이 섞여있을 때는 $\delta_{i j}$ 값의 정도에 따라 MAP 처리 값과 관찰된 영상 화소값을 가중평균해서 얻어지는 값을 사용하는 것이 더 효율적이라 판단된다.

일반적인 MAP 알고리즘에서는 MAP 처리된 $y_{i j}^{M A P}$ 는 입력된 화소값 $x_{i j}$ 를 다음과 같이 처리하여 얻 어진다.

$$
y_{i j}^{M A P}=\operatorname{MAP}\left(x_{i j}\right) .
$$

이에 비해 제안한 $\delta_{i j}$ 값을 사용하는 적응적 MAP 처리과정은 다음과 같이 표현할 수 있다.

$$
y_{i j}^{\text {adap }}=x_{i j} \cdot \delta_{i j}+\operatorname{MAP}\left(x_{i j}\right) \cdot\left(1-\delta_{i j}\right) .
$$

위 식을 보면, 만약 $\delta_{i j}=0$ (영상 잡음)인 경우에는 $\mathrm{MAP}$ 를 가하지 않게 되어 $y_{i j}^{a d a p}=\mathrm{MAP}\left(x_{i j}\right)$ 이 되고, $\delta_{i j}=1$ (영상 특징)인 경우에는 $y_{i j}^{a d a p}=x_{i j}$ 이 되게 된다. 따라서 영상 특징과 영상 잡음의 판별결과를 나타내는 값 $\delta_{i j}$ 에 따라 적응적인 영상처리를 하게 됨을 알 수 있다.

\section{4. 모의실험}

모의실험에서는 위와 같은 공통된 기준 하에서 영상 잡음이 없는 원래의 영상에 정규 분포를 따르 는 영상 잡음을 추가한 후 이를 기존의 영상처리 방법인 MAP, 선행논문에서 제안한 방법들과 본 연구 
Table 1: MSE for the $5 \times 5$ pixel window

\begin{tabular}{ccrrrrr}
\hline \hline Noise Model & Corrupted Image & Bartlett & Levene & KW & Adaptive & \multicolumn{1}{c}{ MAP } \\
\hline$N\left(0,5^{2}\right)$ & 21.04 & 28.09 & 28.78 & 30.52 & 20.40 & 54.61 \\
$N\left(0,7^{2}\right)$ & 42.85 & 34.13 & 34.75 & 36.04 & 29.09 & 71.59 \\
$N\left(0,10^{2}\right)$ & 89.79 & 43.97 & 44.72 & 45.49 & 39.80 & 75.55 \\
$N\left(0,15^{2}\right)$ & 205.11 & 62.37 & 63.92 & 64.36 & 57.62 & 80.64 \\
$N\left(0,20^{2}\right)$ & 364.10 & 84.94 & 87.87 & 89.08 & 76.54 & 89.51 \\
$N\left(0,25^{2}\right)$ & 564.83 & 113.27 & 118.36 & 120.72 & 94.31 & 101.16 \\
$N\left(0,30^{2}\right)$ & 803.73 & 148.21 & 156.15 & 159.95 & 114.50 & 118.01 \\
\hline \hline
\end{tabular}

에서 제안한 방법에 기초한 영상처리방법의 결과들을 다음과 같이 정의되는 MSE 값을 통하여 비교하 였다.

$$
\mathrm{MSE}=\frac{1}{J} \sum_{i} \sum_{j}\left(y_{i j}^{a d a p}-o_{i j}\right)^{2},
$$

여기서 $J$ 는 영상의 전체 화소의 수이고, $o_{i j}$ 는 영상 잡음이 없는 원본영상의 픽셀값이며, $y_{i j}^{a d a p}$ 는 잡음이 있는 영상을 영상처리방법으로 처리한 영상의 픽셀 값이다.

Table 1 의 모의실험 결과는 화소 윈도우의 크기에 따라 구하여진 $\delta_{i j}$ 값에 근거한 적응적(adaptive) $\mathrm{MAP}$ 의 결과를 일반적인 적응적 단순 평활법(Bartlett, Levene, $\mathrm{KW})$ 의 결과와 MAP의 결과를 비교한 것이다.

Table 1의 MSE 값들을 살펴보면, 적응적 MAP 알고리즘의 경우 MSE 값이 가장 좋게 나타났으며, 특히 기존의 MAP와 제안한 적응적 MAP를 비교하여 보았을 때도 MSE 값이 좋게 나타나는 것을 볼 수 있다. 이러한 결과는 본 연구에서 고려한 여러 가지 영상 잡음의 분포에서 모두 동일하였으므로 본 연 구에서 제안한 알고리즘은 영상 잡음의 분포에 상관없이 기존의 MAP 보다 나은 결과를 얻을 수 있으 리라고 판단되며, 그 효용성은 시각적으로도 명확하게 확인할 수 있었다.

본 연구에서 사용한 샘플 영상은 영상처리 분야에서 널리 사용되는 'Lenna' 영상이다. 연구결과의 시각적 비교를 위하여 Figure 10은 'Lenna' 순수영상, $N\left(0,10^{2}\right)$ 을 따르는 영상 잡음으로 인하여 오염된 영상, 기존의 MAP 방법과 본 연구에서 제안하는 적응적 MAP 방법에 근거하여 처리한 결과의 일부분 을 확대하여 보여주고 있다.

\section{5. 결론}

영상처리의 궁극적인 목적은 영상 잡음이 없는 원래의 이미지를 재현하는 것이다. 그러나 원래의 영상에 여러 가지 불가피하게, 통제할 수 없는 원인으로 인해 영상 잡음이 추가되게 되며 따라서 영상 잡음을 제거하거나 이를 최대한 줄이는 잡음제거(noise reduction)는 영상처리 분야에 있어서 매우 중요 한 이슈이다. 본 연구에서는 기존의 영상 잡음 제거 방법 중 하나인 MAP 방법의 문제점을 지적하고, 이를 개선하기 위하여 적응적 MAP 방법을 제안하였다. 기존의 MAP는 영상 전체의 분포를 가지고 최 대 확률을 계산하다보니, 영상 잡음이 섞인 화소값과 그렇지 않은 화소값이 같기만 하면 동일하게 취급 하는 문제점이 있었다. 따라서 적응적 $\mathrm{MAP}$ 는 영상 잡음 영역, 영상 특징 영역, 그리고 영상 잡음과 영 상 특징이 섞여 있는 영역을 수치화 하여 영역별로 MAP를 하는 통계적 알고리즘을 제시하였다. 모의 실험 결과를 통하여 본 연구에서 제안하는 적응적 MAP 알고리즘의 성능이 기존의 MAP 방법보다 현 저하게 우수한 것을 알 수 있었으며 그 효용성은 시각적으로도 명확하게 확인할 수 있었다. 


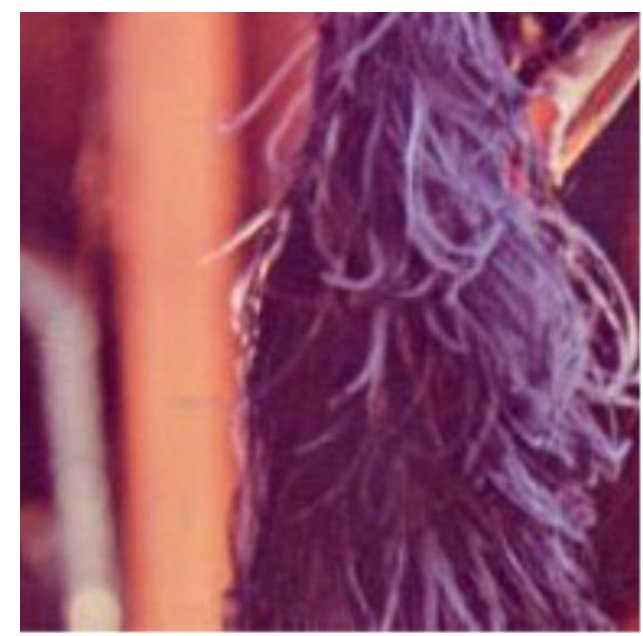

(a) Pure image

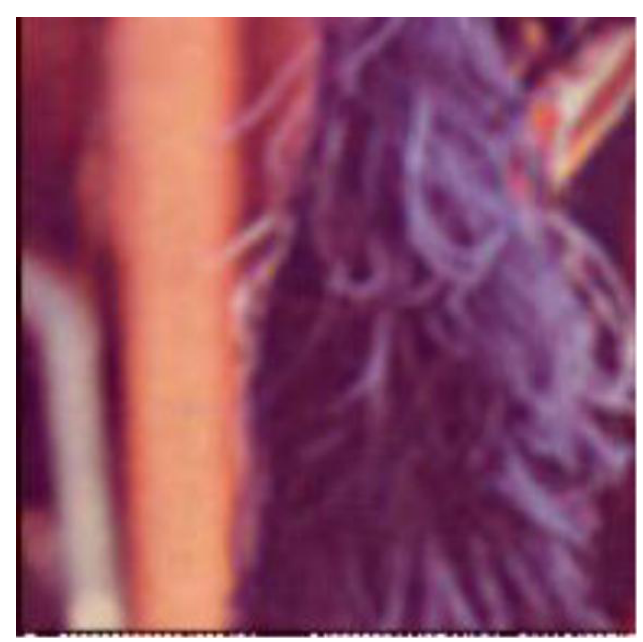

(c) Result of MAP

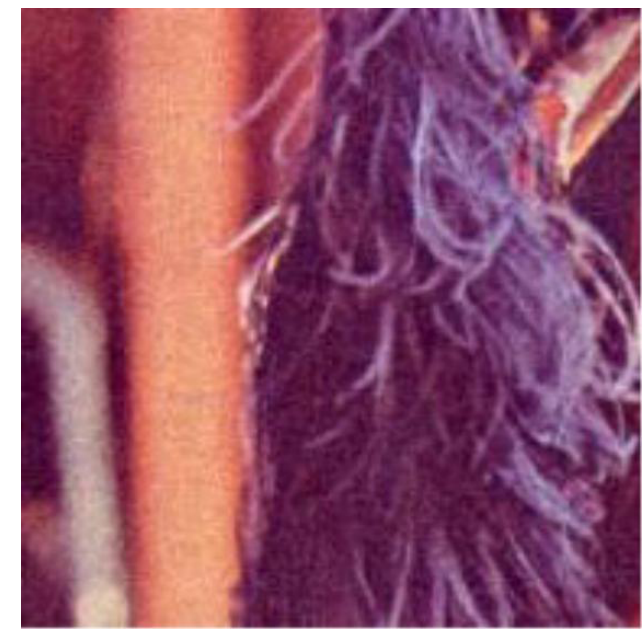

(b) Contaminated image

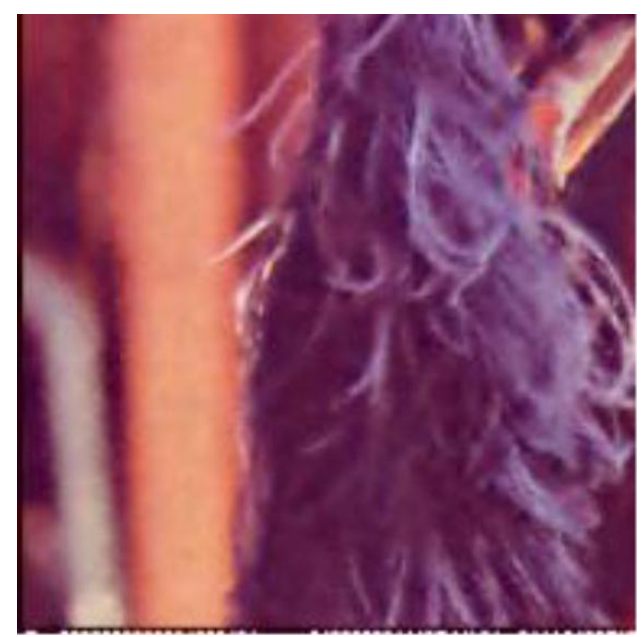

(d) Result of adaptive MAP

Figure 10: Comparison of enlarge 'Lenna' images

\section{References}

Bartlett, M. A. (1937). Properties of sufficiency and statistical tests, Proceedings of the Royal Society of London, Series A, 160, 268-282.

Kim, Y. and Nam, J. (2007). Image feature detection and contrast enhancement algorithms based on statistical test, Journal of Korean Data \& Information Science Society, 18, 385-399.

Kim, Y. and Nam, J. (2008). Deinterlacing algorithms based on statistical tests, Journal of the Korean Data \& Information Science Society, 19, 723-734.

Kim, Y. and Nam, J. (2009). Statistical algorithm and application for the noise variance estimation, Journal of the Korean Data \& Information Science Society, 20, 869-878. 
Kim, Y. and Lee, J. (2005). Image feature and noise detection based on statistical independent tests and their applications in image processing, IEEE Transactions on Consumer Electronics, 51, 1367-1378.

Lee, J., Kim, Y. and Nam, J. (2008). Adaptive noise reduction algorithms based on statistical hypotheses tests, IEEE Transactions on Consumer Electronics, 54, 1406-1414.

Mallat, S. G. (1989). A theory A theory for multiresolution signal decomposition: The wavelet representation, IEEE Transactions on Patttern Analysis and Machine Intelligence, 11, 674-693.

Simoncelli, E. P. and Adelson, E. H. (1996). Noise removal via Bayesian wavelet coring, In Proceedings of 3rd IEEE International Conference on Image Processing, 1, 379-382.

2012년 4월 30일 접수; 2012년 6월 5일 수정; 2012년 6월 11일 채택 